\title{
Optimization of Diauxienne Growth of Pseudomonas aeruginosa in the Bioremediation of Soils Polluted by Hydrocarbons
}

\author{
Bassirou Mahamadou Harouna ${ }^{1,2 *}$ and Othmane Benkortbi ${ }^{1}$ \\ ${ }^{1}$ Industrial Process Engineering and Control Analysis Laboratory (GEPICA), Ecole \\ des Hautes Etudes en Génie de l'Eau, des Procédés Industriels et de l'Environnement \\ (HEGEPRINE), Niamey, Niger \\ ${ }^{2}$ Laboratory of Biomaterials and Transport Phenomena (LBMPT), Department of \\ Engineering Process and Environment. Faculty of Technology, University Dr Yahia Fares \\ of Medea - Algeria, Algeria \\ *Corresponding Author: Bassirou Mahamadou Harouna, Industrial Process Engineering \\ and Control Analysis Laboratory (GEPICA), Ecole des Hautes Etudes en Génie de l'Eau, des \\ Procédés Industriels et de l'Environnement (HEGEPRINE), Niamey, Niger and Laboratory \\ of Biomaterials and Transport Phenomena (LBMPT), Department of Engineering Process \\ and Environment. Faculty of Technology, University Dr Yahia Fares of Medea - Algeria, \\ Algeria.
} Received: February 27, 2020 Published: April 13, 2020 (c) All rights are reserved by Bassirou Mahamadou Harouna and Othmane Benkortbi.

\section{Abstract}

The objective assigned to this study is the optimization of azote nutriment source for the microbial bioremediation to contribute to the fight against environmental pollution through the production of biosurfactants of multidisciplinary interest. This study consists in metabolizing hydrocarbons into biosurfactants using Pseudomonas aeruginosa ATCC 27853 strain in order to control the environmental threat in a batch of $250 \mathrm{ml}$ at $37^{\circ} \mathrm{C}$ for 48 hours of culture. The optimization tests of nitrogen source showed that within a range of concentration [1 - 8] g/l, the optimum value was $4 \mathrm{~g} / \mathrm{l}$ for $\mathrm{KNO}_{3}$ with an emulsification index EI24 = 71.45\% and an optical density DOX $=0.55$ for $46 \mathrm{~h}$ of culture. The yields obtained $\mathrm{Y}_{\mathrm{x} / \mathrm{s}}$ and $\mathrm{Y}_{\mathrm{p} / \mathrm{s}}$ were of $60.00 \%$ and $32.17 \%$ respectively with an amount of biosurfactants $\mathrm{P}=580 \mathrm{mg}$, a bioconversion rate $\theta=78.47 \%$ and a ratio $\mathrm{N} / \mathrm{C}=0.473$. The comparative study between two nitrogen sources such as $\mathrm{KNO}_{3}$ and $\mathrm{NH}_{4} \mathrm{NO}_{3}$ for a range of concentration [3 - 4] g/l demonstrated that the best source of nitrogen remains $\mathrm{KNO}_{3}$. Indeed, the kinetic monitoring of the biomass growth, the emulsification index, the biosurfactants productivity and the substrates consumption revealed the inhibition of the strain by $\mathrm{NH}_{4} \mathrm{NO}_{3}$ after 7 hours of incubation, provoking the degeneration of the strain and slowing the removal of pollutants process. A similar study of $\mathrm{NH}_{4} \mathrm{NO}_{3}$ at a concentration of $4 \mathrm{~g} / \mathrm{l}$ resulted in an emulsification index EI24 $=65.22 \%$, a yields $\mathrm{Y}_{\mathrm{x} / \mathrm{s}}=18.37 \%$ and $\mathrm{Y}_{\mathrm{p} / \mathrm{s}}=45.17 \%$ and a bioconversion rate $\theta=57.36 \%$. The amount of the biosurfactants measured at $\mathrm{P}=590 \mathrm{mg}$ for an $\mathrm{N} / \mathrm{C}$ ratio of 0.739 . In fact, the results of this study demonstrated that $\mathrm{KNO}_{3}$ promotes the growth of biomass as well as the production of biosurfactants who play a major role in the enrichment of the soil by solubilizing the toxic elements and a maximum removal of hydrocarbons following diauxic phenomena.

Keywords: Pollution; Environment; Bioremediation; Biosurfactants; Optimization

\section{Introduction}

The infiltration and the dispersal of hydrocarbons in the underground constitute a major threat for the whole ecosystem due to their pollution of the shallow ground waters [1]. According to the CETESB (1996) and the Brazilian agency of environmental control, hydrocarbons spraying covers $78 \%$ of the soil contamination which represents $90 \%$ of the crude oil in the environment and affects water sources destined for the consumption leading to a major public health problem due to the toxic properties (mutagenic and carcinogenic of the aromatic compounds) [1,2].

The bioremediation by the bacteria is based on their ability to degrade crude oil compounds through a process of assimilation as a source of carbon and energy during growth metabolism, resulting in complete mineralization of constituents [3].
The efficiency of the bioremediation process depends on several factors such as. The presence of microorganisms with catabolic capacities adapted to contaminants at the site or an inductive enzyme metabolism as Pseudomonas aeruginosa; presence of nutriments and physicochemical conditions favorable for the growth and for the secondary metabolism of production of xenobiotic compounds of the hydrophobic solubilization compound (biosurfactant); the composition, the concentration and the bioavailability of the contaminant. The two techniques widely used in the bioremediation are the bio-stimulation by a supply of nitrogen and phosphate the growth and the bio-increase [4,5]. Moreover, the use of biosurfactants such as rhamnolipids produced by Pseudomonas aeruginosa has proven to be very effective in the bioremediation of soils contaminated by hydrocarbons (David., et al. 2017; Eman and Andrew 2017). 
Biosurfactants are surfactant amphiphilic molecules, which decrease the superficial and interfacial tension of the medium by solubilizing the crude oil compounds (Magdalena., et al. 2011). They are biodegradable, specific, highly selective and are active under extreme conditions of temperature, of salinity and of $\mathrm{pH}$, Ellen., et al [1].

Their mechanism of action in very small amount is based on the formation of micelles by emulsification of the oil/water or water/oil medium. Biosurfactants participate in the mobilization, the solubilization and the emulsification of the contaminated medium by hydrocarbons (Magdalena., et al. 2011).

The bacteria of the kind Pseudomonas are characterized by a multitude of enzymes of synthesis of biosurfactants and their induction in a mean where the phosphate and the nitrogen are factor limitants. Pseudomonas aeruginosa synthesizes rhamnolipid biosurfactants in response to stimulus, which are hydrocarbons [1]. The enzymes involved in the conversion of hydrocarbons are of two types: rhamnotransferase I and II with auto-inductive capacity. Their induction results in the synthesis of several rhamnolipids (Rodrigo., et al. 2011).

\section{Purpose of the Study}

The main purpose of this study is to elucidate the auto-inductive capacity of Pseudomonas aeruginosa ATCC 27853 in the bioremediation of grounds polluted by the crude oil through biostimulation combined with biosurfactants. The kinetic monitoring focused on the inductive growth kinetic (diauxic phenomena of the biomass), the emulsification of the medium, the productivity of the biosurfactant and the consumption of the carbon substrate by optimization of the quality and the quantity of the nitrogen source.

\section{Material and Experiment}

Preparation of the study site

The Niger Delta was chosen in view of the extent of the damage to the environment caused by the spills of crude oil several hectares of agricultural land and pasture and the water resources for consumption and fishing. It is a clay soil harvested from 10 localities that were heavily contaminated according to the study by Amnesty International (2015). Sampling was carried out using tubes $14.50 \mathrm{~cm}$ long and $1.50 \mathrm{~cm}$ in diameter at a depth of $8-10 \mathrm{~cm}$ from the ground. Thus, all the tubes were conditioned with $1 \mathrm{ml}$ sulfuric acid at $9 \mathrm{~N}$ in situ and placed under sterile conditions at $-13^{\circ} \mathrm{C}$ before pretreatment in the laboratory, AL-Saleh and Akbar [6].

The strain Pseudomonas aeruginosa ATCC 27853 was kindly supplied from Medea hospital (Algeria) and was stored in the laboratory under freezing temperature. It was activated on a cetrimide agar in a petri dish and then seeded on the germination medium containing a mixture of heptane and cetane as a source of carbon and energy. The culture medium was formulated according to the work of Milena., et al [7].
Fertilizers were successively added with $3 \%(\mathrm{P} / \mathrm{V})$ of the pretreated contaminated soil in $250 \mathrm{ml}$ of distilled water under agitation for 5 minutes for homogenization. The medium was adjusted to a pH of $6.00 \pm 0.01$ by addition of sodium hydroxide (1N) hydrochloric acid $(1 \mathrm{~N})$ and was sterilized for 15 minutes at $121^{\circ} \mathrm{C}$ in the autoclave $[8,9]$. The culture medium was cooled to $70^{\circ} \mathrm{C}$; the $\mathrm{pH}$ was adjusted to $7.00 \pm 0.01$ before seeding. The culture was carried out in a batch with an agitation speed of $250 \mathrm{rpm}$ at $37^{\circ} \mathrm{C}$ for $48 \mathrm{~h}$ [9].

\section{Kinetic monitoring}

Biomass growth monitoring was carried out using optical density method at $600 \mathrm{~nm}[6,10]$. Samples of $10 \mathrm{ml}$ of the fermented medium were taken at regular time intervals and were centrifuged at $6000 \mathrm{rpm}$ for 10, 15 and 20 minutes successively with pellet removal. The pellet was washed with distilled water to remove residues from the culture medium and then centrifuged at $6000 \mathrm{rpm}$ for 20 minutes. The biomass was dried in an oven for $24 \mathrm{~h}$ at $105^{\circ} \mathrm{C}$ [10-12]. The dry weight of the biomass was determined from the following relationship: $($ Biomass $=$ Dry weight $\times 0.44$ ) for all experiments (Palashpriya and Luyan 2013).

To determine the emulsification index $\mathrm{EI}_{24} \%, 2 \mathrm{ml}$ of the acellular medium obtained after centrifugation by removal of the pellet were taken and completed with $2 \mathrm{ml}$ of hexadecane and were placed in a vortex for 5 minutes. The emulsified samples were then left at rest and the emulsification index was measured after $24 \mathrm{~h}$ $[10,12]$.

The crude biosurfactant produced by the $P$. aeruginosa strain was isolated by acid precipitation from the cell-free supernatant $[10,12,13]$. The medium devoid of residual fragments was precipitated by addition of absolute ethanol with a slight agitation until the precipitation of the total amount of the biosurfactant contained in the supernatant [8].

The obtained biosurfactant was washed with distilled water to eliminate as much as possible the traces of ethanol and dried in a vacuum desiccator, then was weighed and expressed in $\mathrm{g} / \mathrm{L}$ of the culture medium. The amount of hydrocarbons contained in the homogenized mixture of 10 samples taken from the soil was determined by COD-Spectrophotometric at $600 \mathrm{~nm}$ using a UV/VIS spectrophotometer GBC 101 Scientific Equipment, driven by the "Cintral ver 2.3" software with a resolution of $0.1[14,15]$.

\section{Optimization of the culture conditions}

The nitrogen source is a determining factor for the bioremediation of soil contaminated by hydrocarbons process efficiency. Therefore, two sources of nitrogen were optimized as a limiting factor, namely: $\mathrm{KNO}_{3}$ and $\mathrm{NH}_{4} \mathrm{NO}_{3}$ within a range [1 - 8] g/l for $\mathrm{KNO}_{3}$ and $[3-4] \mathrm{g} / \mathrm{l}$ for $\mathrm{NH}_{4} \mathrm{NO}_{3}$ in a medium rich of carbon for a total volume of $250 \mathrm{~mL}$ without renewal during $48 \mathrm{~h}$ at $37^{\circ} \mathrm{C}$ with $\mathrm{pH}=7$. The limitation of concentration of $\mathrm{NH}_{4} \mathrm{NO}_{3}$ is related to the inhibi- 
tory and repressive effect of $\mathrm{NH}_{4}$ on the strain containing a highdose in the medium $[4,5,14]$.

\section{Results and Discussion}

The choice of Pseudomonas aeruginosa in bioremediation was based on its ability to grow in a poor medium of nutrient and its enzymatic induction genome characteristic. The optimization of the pollutant removal process was based on the nitrogen source and constitutes a performance process of bioremediation. This impact, not only microbial growth, but also biosurfactant productivity as a factor of mobilization, solubilization and emulsification of the polluted medium for the degradation of hydrocarbons. All experiments carried out in this study were repeated three times in order to guarantee the reproducibility of the results in a range of confidence of $95 \%$ by the statistical analysis on the correlation coefficient. The results of nitrogen optimization for $\mathrm{NO}_{3}$ are presented in figure 1 below.

The effectiveness of the bioremediation process depends on several factors including the microorganism growth in proportion to anaerobic respiration metabolism. This growth of Pseudomonas aeruginosa as shown in the results of figure $1 \mathrm{a}$ is maximal, in proportion to the emulsification index and the amount of the biosurfactant in the medium (Figure $1 \mathrm{~b}$ ) at $4 \mathrm{~g} / \mathrm{l} \mathrm{NO}_{3}$. This proportionality between these three factors characterizes a process of mobilization, solubilization and elimination of hydrocarbons contaminating the medium due to the limitation of nitrogen in the presence of a high concentration of carbon and energy sources, $\mathrm{C}_{\mathrm{s}}$ $=9107 \mathrm{mg} / \mathrm{L}$, in accordance with the observations of Magdalena., et al (2011).

Moreover, the bioconversion rate (Figure 1a) shows that the maximum elimination is obtained at $8 \mathrm{~g} / \mathrm{L}$. This inversion of proportionality with other factors is characteristic of the abundance of nitrogen in the medium reorienting the metabolism of the strain. The impact of this abundance influences the biosurfactant production in the medium as shown by the evolution of the emulsification index (Figure 1b). The results found are in accordance with the observations of Tyagi., et al. [4], Taccari et al. [5], Vanessa., et al. 2014; Joanna et al. on the production of biosurfactants and the removal of oils. On the other hand, the evolution of the N/C ratio and the yield of biomass $Y_{x / s}$ against the nitrogen amount shows that the conversion rate is a performance factor of the bioremediation process (Figure 1c).

Figure $1 \mathrm{~d}$ characterizes the type of diauxic phenomenon of the Pseudomonas aeruginosa strain in the medium. This diauxienne growth implements enzymes entering within the scope of the conversion of hydrocarbons by Pseudomonas aeruginosa which are of two types namely rhamnotransferase I and II with auto-inductive capacity. Their induction is at the origin of the synthesis of several rhamnolipids, Rodrigo., et al (2011). In fact, the emulsification is a key factor of the bioremediation process and this is in adequacy with the growth, the biosurfactant productivity, the yield, the elimination rate and $\mathrm{N} / \mathrm{C}$ ratio for a concentration of $\mathrm{KNO}_{3}=4 \mathrm{~g} / \mathrm{L}$ as shown in figure $1 \mathrm{a}-1 \mathrm{~d}$.
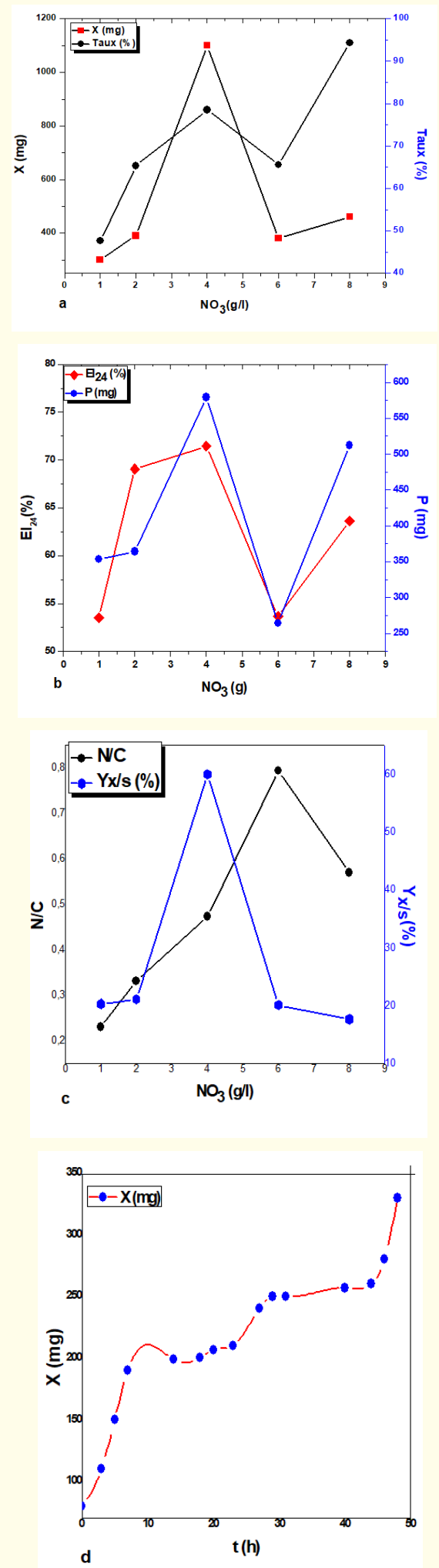

Figure 1: Maximum growth of Pseudomonas aeruginosa and biodegradation rate of hydrocarbons, (b) Emulsification index of the contaminated medium and the amount of the biosurfactant produced against the concentration of $\mathrm{NO}_{3}$. 
However, the change of the nitrogen source showed that the quality of nitrogen affects considerably the efficiency of the bioremediation process. The ammonium ion has an inhibitory effect on the growth of Pseudomonas aeruginosa (Table 1). This inhibition is at the origin of the blocking of the quorum sensing synthesis whose maturity is essential for the growth and the production of secondary metabolites in the fermentative medium. The results are depicted in table 1. El-Sheshtawy and Doheim [14] in their work, observed the same behavior of Pseudomonas aeruginosa in the presence of the ammonium ion.

\begin{tabular}{|c|c|c|c|c|c|c|c|c|}
\hline \multicolumn{10}{|c|}{ Parameters } \\
\hline & $\mathbf{P}(\mathbf{m g})$ & $\boldsymbol{\theta} \%$ & $\mathbf{Y}_{\mathrm{x} / \mathbf{s}} \mathbf{\%}$ & $\mathbf{Y}_{\mathrm{p} / \mathbf{s}} \mathbf{\%}$ & $\mathbf{E I}_{\mathbf{2 4}} \mathbf{\%}$ & $\mathbf{N} / \mathbf{C}$ & $\mathbf{X}_{\mathbf{0}}$ & $\mathbf{X}_{\text {max }}$ \\
\hline 3 g/l & 341,10 & 54,29 & 30,74 & 27,59 & 61,90 & 0,4362 & 0,08 & 0,42 \\
\hline 4 g/l & 590,00 & 57,36 & 18,37 & 45,17 & 65,22 & 0,7309 & 0,08 & 0,33 \\
\hline
\end{tabular}

Table 1: Results of the evaluation of $\mathrm{NH}_{4} \mathrm{NO}_{3}$ on the performance of the bioremediation process ( $\mathrm{X}_{0}$ and $\mathrm{X}_{\max }$ in $\mathrm{mg}$ ).

In comparison of the results with the $\mathrm{KNO}_{3}$, growth is three times less important as a first factor of the efficiency of bioremediation processes that characterizes a biosurfactant productivity yield of $2 / 3$ compared with $\mathrm{KNO}_{3}=4 \mathrm{~g} / \mathrm{l}$. Despite emulsification $\mathrm{EI}_{24}=65,22 \%$, the conversion rate does not exceed less than $60 \%$ of the total amount of hydrocarbons in the medium. The effect of the ammonium ion also affects the process of mobilization, solubilization and emulsification by affecting the quality of the biosurfactants in spite of a maximum amount produced $\mathrm{P}=590 \mathrm{mg}$ for $\mathrm{NH}_{4} \mathrm{NO}_{3}=4 \mathrm{~g} / \mathrm{l}$, according to the conversion rate [16-27].

\section{Conclusion}

The synthesized biosurfactants have a great potential to solubilize the oils contained in the polluted soils, to reduce the surface tension and the interfacial tension of the immiscible liquids and to modify the diameter of the oil in the water. The objective was to produce biosurfactant microbially using hydrocarbons contained in sludge as a source of carbon and energy. The experiments carried out in this study showed that potassium nitrate is the best source of nitrogen for the Pseudomonas aeruginosa strain in the process of bioremediation of contaminated soils by hydrocarbons. Moreover, the results demonstrated that Pseudomonas aeruginosa is able to grow on several sources of carbon and energy, which characterize the complex medium formed by petroleum hydrocarbons polluting the soil. The optimization of the diauxienne growth capacity allows a more efficient bioremediation of soils polluted by hydrocarbons.

Indeed, the obtained results showed that ammonium nitrate increases the kinetic time of the pollutants removal process because of the inhibitive effect of the ammonium ion on the strain. Which not only reduces the possibility of enriching the soil with biosurfactant of a good quality of mobilization, solubilization and emulsification of the medium, but also increases the consumption of nitrogen for low conversion rates and decrease the speed of the removal of the pollutants.

\section{Bibliography}

1. Winquist E., et al. "Bioremediation of PAH-contaminated soil with fungi-From laboratory to field scale". International Biodeterioration and Biodegradation 86 (2014): 238-247.

2. Janbandhu A and Fulekar MH. "Biodegradation of phenanthrene using adapted microbial consortium isolated from petrochemical contaminated environment". Journal of Hazardous Materials 187.1-3 (2011): 333-340.

3. Haderlein A., et al. "Pyrene mineralization capacity increases with compost maturity". Biodegradation 17.4 (2006): 293302.

4. Tyagi M., et al. "Bioaugmentation and biostimulation strategies to improve the effectiveness of bioremediation processes". Biodegradation 22.2 (2011): 231-241.

5. Taccari M., et al. "Effects of biostimulation and bioaugmentation on diesel removal and bacterial community". International Biodeterioration Biodegradation 66.1 (2012): 39-46.

6. AL-Saleh E and Akbar A. "Occurrence of Pseudomonas aeruginosa in Kuwait soil”. Chemosphere 120 (2015): 100-107.

7. Milena GR., et al. "Production and characterization of rhamnolipids from Pseudomonas aeruginosa san-ai". Journal of the Serbian Chemical Society 77 (2012): 27-42.

8. Graziela JP., et al. "Production of Biosurfactants by Rhodococcus erythropolis and their application for enhance to remove oil". Brazilian Journal of Microbiology 41.3 (2010): 1-7.

9. Atipan S., et al. "Biosurfactant production by Bacillus subtilis TD4 and Pseudomonas aeruginosa SU7 grown on crude glycerol obtained from biodiesel production plant as sole carbon source". Journal of Scientific and Industrial Research 71.6 (2012): 396-406.

10. Kumar AP., et al. "Evaluation of orange peel for biosurfactant production by Bacillus licheniformis and their ability to degrade naphthalene and crude oil". 3 Biotech 6.1 (2016): 43.

11. Raquel DR., et al. "Characterization and properties of the biosurfactant produced by Candida lipolytica UCP 0988". Electronic Journal of Biotechnology 17.1 (2014): 34-38. 
12. Samira F., et al. "Production and characterization of biosurfactant by free and immobilized cells from Ochrobactrum intermedium isolated from the soil of southern Algeria with a view to environmental application". Biotechnology and Biotechnological Equipment 31.4 (2017): 733-742.

13. Das K and Mukherjee AK. "Crude petroleum-oil biodegradation efficiency of Bacillus subtilis and Pseudomonas aeruginosa strains isolated from a petroleum-oil contaminated soil from North-East India". Bioresource Technology 98.7 (2007): 1339-1345.

14. El-Sheshtawy HS and Doheim MM. "Selection of Pseudomonas aeruginosa for biosurfactant production and studies of its antimicrobial activity". Egyptian Journal of Petroleum 23.1 (2014): 1-6.

15. Musa NM., et al. "Bioremediation of Petroleum Refinery Wastewater Effluent via Augmented Native Microbes". Journal of Emerging Trends in Engineering and Applied Sciences (JETEAS) 6 (2015): 1-6.

16. Souza EC., et al. "Biosurfactant-enhanced hydrocarbon bioremediation: An overview". International Biodeterioration and Biodegradation 89 (2014): 88-94.

17. Cerqueira VS., et al. "Comparison of bioremediation strategies for soil impacted with petrochemical oily sludge". International Biodeterioration and Biodegradation 95 (2014): 338-345.

18. Brzeszcz J., et al. "r-strategist versus K-strategist for the application in bioremediation of hydrocarbon-contaminated soils". International Biodeterioration and Biodegradation 106 (2016): 41-52.

19. Górna H., et al. "Differences and dynamic changes in the cell surface properties of three Pseudomonas aeruginosa strains isolated from petroleum-polluted soil as a response to various carbon sources and the external addition of rhamnolipids". Bioresource Technology 102.3 (2011): 3028-3033.

20. Reis RS., et al. "Gene regulation of rhamnolipid production in Pseudomonas aeruginosa-A review". Bioresource Technology 102.11 (2011): 6377-6384.

21. Yan P., et al. "Oil recovery from refinery oily sludge using a rhamnolipid biosurfactant-producing Pseudomonas". Bioresource Technology 116 (2012): 24-28.

22. Das P and Ma LZ. "Pyocyanin pigment assisting biosurfactantmediated hydrocarbon emulsification". International Biodeterioration and Biodegradation 85 (2013): 278-283.
23. Rocha e Silva NMP., et al. "Screening of Pseudomonas species for biosurfactant production using low-cost substrates". Biocatalysis and Agricultural Biotechnology 3.2 (2014): 32-139.

24. Brown DM., et al. "Comparison of landfarming amendments to improve bioremediation of petroleum hydrocarbons in Niger Delta soils". Science of the Total Environment 596-597 (2017): 284-292.

25. Koshlaf E and Ball AS. "Soil bioremediation approaches for petroleum hydrocarbon polluted environments”. AIMS Microbiology 3 (2017): 25-49.

26. Pacwa-Płociniczak M., et al. "Environmental Applications of Biosurfactants: Recent Advances". International Journal of Molecular Sciences 12 (2011): 633-654.

27. Kildisas V., et al. "Development of clean-up complex technology of soil contaminated by oil pollutants based on cleaner production concepts". Environmental Resource Engineering Management 25 (2003): 87-93.

\section{Assets from publication with us}

- Prompt Acknowledgement after receiving the article

- Thorough Double blinded peer review

- Rapid Publication

- Issue of Publication Certificate

- High visibility of your Published work

Website: https://www.actascientific.com/

Submit Article: https://www.actascientific.com/submission.php Email us: editor@actascientific.com

Contact us: +919182824667 